\title{
Modeling for Underground Cable Water Tree Growth Dynamics
}

\author{
Sola Famakin*, Charles Kim \\ Electrical Engineering and Computer Science Department, Howard University, Washington DC, USA \\ Email: *sola.famakin@howard.edu, ckim@howard.edu
}

How to cite this paper: Famakin, S. and Kim, C. (2019) Modeling for Underground Cable Water Tree Growth Dynamics. Journal of Power and Energy Engineering, 7, 51-65.

https://doi.org/10.4236/jpee.2019.712004

Received: November 5, 2019

Accepted: December 27, 2019

Published: December 30, 2019

Copyright $\odot 2019$ by author(s) and Scientific Research Publishing Inc. This work is licensed under the Creative Commons Attribution International License (CC BY 4.0).

http://creativecommons.org/licenses/by/4.0/

(c) (i) Open Access

\begin{abstract}
Underground cable faults, whether transient or permanent, are traceable to insulation failure problems, most of which are water tree initiated. Insulation breakdown, which usually leads to costly power outages, may be prevented by taking pre-emptive actions. The most decisive pre-emptive action is one in which real-time tracking of water tree advancement within the cable insulation system is possible. Such pre-emptive actions, however, depend on accurate modeling of the phenomenon. Earlier water tree models are static in that they focused on the cable insulation property change at a time segment. Thus, they lack the properties needed for tracking water tree progress and for determining the onset of transient and permanent faults. This paper presents a new approach to water tree modeling, focused on insulation degradation geometry in the form of parabolic expansion of water tree. We developed a dynamic model centered on the computation of the capacitance of a vented water tree as a function of time. The dynamic model accounts for the time-dependence of the radial growth of the water tree to track insulation degradation. The model was tested in predicting cross-linked polyethylene (XLPE) cable's insulation lifespan. The result was found to be within the range of the recorded lifespan of field aged cables in the literature. Also, performance comparison with an earlier analytical model validated with COMSOL Hyperphysics software shows a significant correlation between them.
\end{abstract}

\section{Keywords}

Insulation, Modeling, Treeing, Capacitance, Permittivity

\section{Introduction}

The water treeing phenomenon is an insulation degradation process that progresses slowly, silently and out of sight, undermining the insulation of in-service underground power cables until breakdown occurs. Because of the 
critical nature of the problem to power system reliability, this subject has been vigorously researched for well over three decades. The researches were majorly focused on understanding the dynamics of water tree formation, the sequence of events leading to its morphology into full-blown insulation degradation, and the circumstances of insulation breakdown emerging from it. Mostly, the presence of micron-size particulate impurities within the body of insulation or at any of the interfaces, microvoids due to a manufacturing defect, irregularities at the internal interfaces leading to protrusions and local electric field enhancement, and cracks within the insulation system arising from aging are some of the significant causes identified in the literature [1] [2]. However, another common source of water treeing, which usually results in insulation breakdown over time, stems from external injuries to a cable's insulation during transport, installation, or maintenance. This occurrence, aided by the powerful electric field created when the cable is energized, encourages the seepage of moisture into the insulation system, thus commencing the water treeing phenomenon. Over time, as water tree growth advances towards the conductor, the thickness of sound insulation between it and the outer screen reduces. At this point, a transient condition, such as a switching surge generating a momentarily considerable electric stress can result in a breakdown, leading to an earth fault. The intricacies of the identified causes of water tree formation and growth may be summarized as the result of interplaying electromechanical and electrochemical forces within the polymeric insulation system. These forces are set in motion when the twin factors of moisture and a strong, time-varying electric field are present within the insulation systems.

As the demand for a very high degree of reliability and quality electric power continues to take central focus in the management of electric power systems, it becomes imperative to look more closely at the causes of failure in critical power infrastructures such as underground cable systems and how such failure can be prevented. Detecting early warning signs of failure, and being able to track its advancement are means of preventing such failures and the power outage that would have resulted from it. In this paper, we provide a focus on a new water tree modeling methodology that is supportive of cable insulation failure tracking and power outage prevention.

\section{Background}

\subsection{XLPE Cable Construction and the Water Treeing Phenomenon}

The Cross-linked Polyethylene (XLPE) cable is popular in medium-high voltage power transmission and distribution applications. Figure 1 shows the cross-sectional feature of a single core XLPE cable. A detailed description of the components and their functions are provided by [1]. The strength of the cable's polymeric insulation lies in the cross-linking process, which modifies the polymer's basic structure and gives it much more improved properties. The end-product is stronger, more tolerant of excessive temperature resulting from overloading in 
transient and steady-state conditions, more flexible and possesses good dielectric properties that are supportive of applications in a wide range of operational voltage. These improvements, therefore, place it at an advantage, especially in applications requiring operational voltages that are up to $500 \mathrm{kV}$. In spite of its many advantages, XLPE cables are still susceptible to the water treeing problem which is a major cause of insulation failure.

There are three main types of water trees, as illustrated in Figure 2(a). The first is the bow-tie water trees, which are so named because of its resemblance to a bow-tie. They are usually formed within the insulation and constitutes no threat of insulation breakdown. The second and most troublesome class of all is the vented water tree, which may be formed at any of the interfaces. It is the main culprit in most insulation breakdown occurrences, mainly when formed at the outer (insulation-screen) interface [3]. Figure 2(b) illustrates how a vented water tree can result in insulation breakdown. Bush trees, which is an aggregation of many vented water trees, is the third class. It may be formed at any of the interfaces and constitute no risk of insulation breakdown.

\subsection{Water Tree Modeling}

The study of water trees for preemptive actions to forestall insulation breakdown requires adequate modeling of the phenomenon. Three basic approaches have been used in the literature. They are analytical approaches, use of modeling and simulation software such as COMSOL Hyperphysics, and laboratory-moderated accelerated insulation aging processes [4] [5]. The analytical approach to water tree modeling requires the identification of a representative physical geometry of

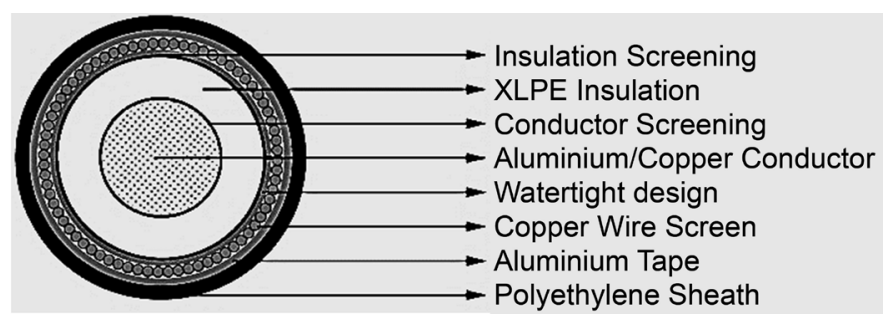

Figure 1. A cross-sectional view of an XLPE cable. Courtesy [1].

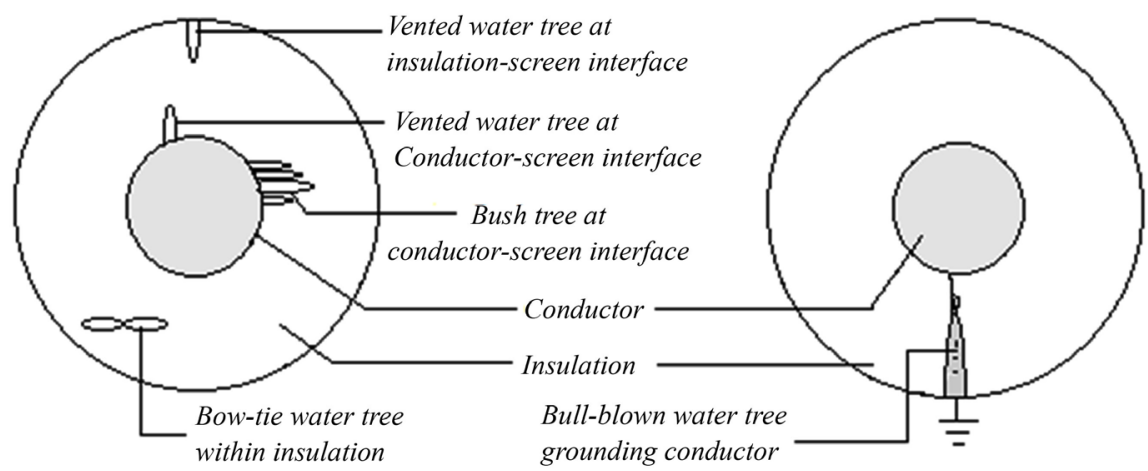

(a)

(b)

Figure 2. Cross-sectional view of XLPE cable showing types of water trees. 
the problem [6] [7]. Using such geometries, researchers have sought to model the problem as a changing permittivity or conductivity of insulation material with the growth of water trees or both.

The nature of modern power systems and the demand for a very high degree of reliability requires proactive approaches to dealing with faults to ensure system protection, safety, and service continuity. Consequently, of late, research activities aimed at modeling water trees for practical applications such as fault diagnosis in underground power systems were carried out by [8] [9] [10], among many others. However, the earlier water tree models are unsuitable for tracking water tree growth, identifying potential signs of impending insulation breakdown, and preventing it because of their staticity. This is because those models can only provide information about the state or behavior of failing insulation at a time segment. Because of this shortcoming, we introduce in this paper, the concept of water tree dynamic model. The dynamic model allows the computation of water tree capacitance as a function of time. Hence, it provides an insight into the state of an underground cable's insulation at every time segment during its lifetime. The steps taken to develop this model are presented in this paper.

\subsection{Nature and View of Water Trees}

Water trees are dendritic growths of micro-defects within the insulation of polymeric cables. [11] proposed and experimentally verified a mechanical damage theory of polymeric insulation. His result shows that the dendrites are made up of ellipsoidal pockets of water of microscopic sizes connected by tubular channels, which, under a microscope, looks like strings of pearls (Figure 3). Each microvoid is separated from the next by about $3 \mu \mathrm{m}$ of tubular channels with an approximated radius of $40 \mathrm{~nm}$. Both the channels and the ellipsoidal microvoids are usually filled with water. Each of the pearly string of water ellipsoids is surrounded by XLPE insulation whose varying degrees of degradation determines the overall electrical permittivity of the area. A degraded area of insulation that contains these dendritic strings of water micro-pockets is referred to as a water tree. The overall approximate geometrical structure depends on the magnitude of the electric field, the system operating frequency, and the water content [12]. Figure 3 shows a view of this area and an enlarged view of each water micro-void, respectively.

While the geometrical feature of water trees can be quite random, it has been discovered that vented water trees that grew in field aged cables which were operated at power frequency $(50-60 \mathrm{~Hz})$ and high voltages usually maintain approximately parabolic geometry as illustrated in Figure 4(a) [12] [13]. This shape illustrates how an inward-growing vented water tree can be a potential source of insulation breakdown. The approximate geometry of the vented water tree which is reproduced in Figure 4(b) has three major parts, namely the root, the body, and the front. The modeling activities presented in the following sections of this paper are motivated in part by this geometrical feature. 


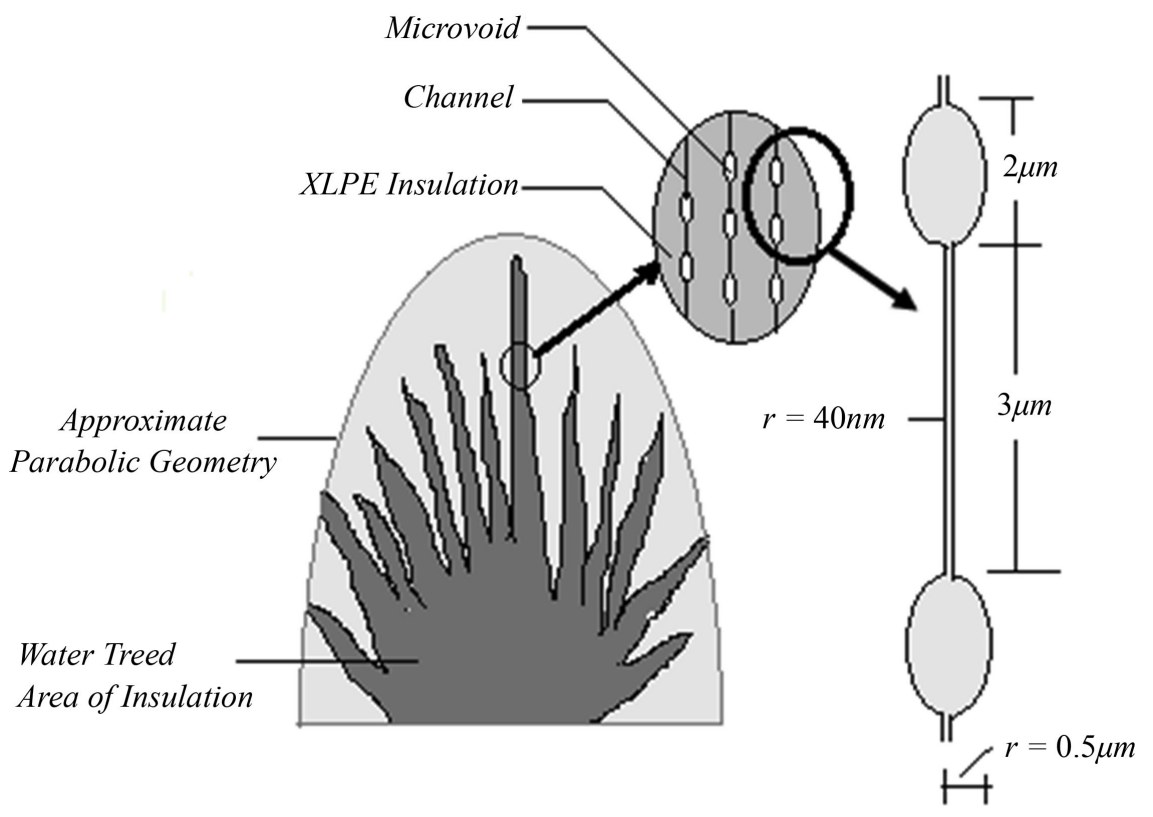

Figure 3. Microstructural view of water tree [11].

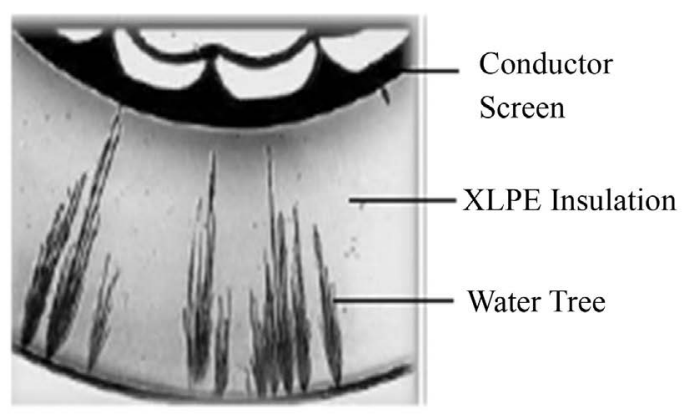

(a)

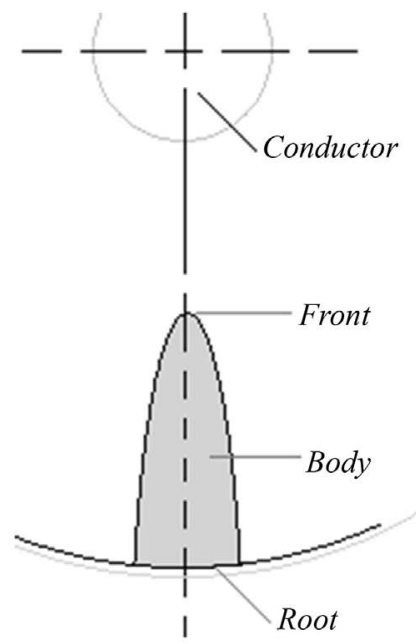

(b)

Figure 4. The geometry of vented water tree. (a) A cross-sectional view of Field Aged XLPE cable showing Vented water Trees; (b) Structure of Vented Water Tree.

\section{Methodology}

\subsection{Conceptualization of a Water Tree Geometry for Dynamic Modeling}

As earlier proposed, the cross-sectional view of a vented water tree, as seen in Figure 3 and Figure 4, is approximately parabolic. According to [14], vented water tree growth progresses in cyclic layers. Following this report, each new layer of growth would be approximately parabolic in shape resulting in an axial growth towards the conductor with each layer. In building the vented water tree dynamic model (Figure 5), which illustrates a simplified and enlarged sector of the 


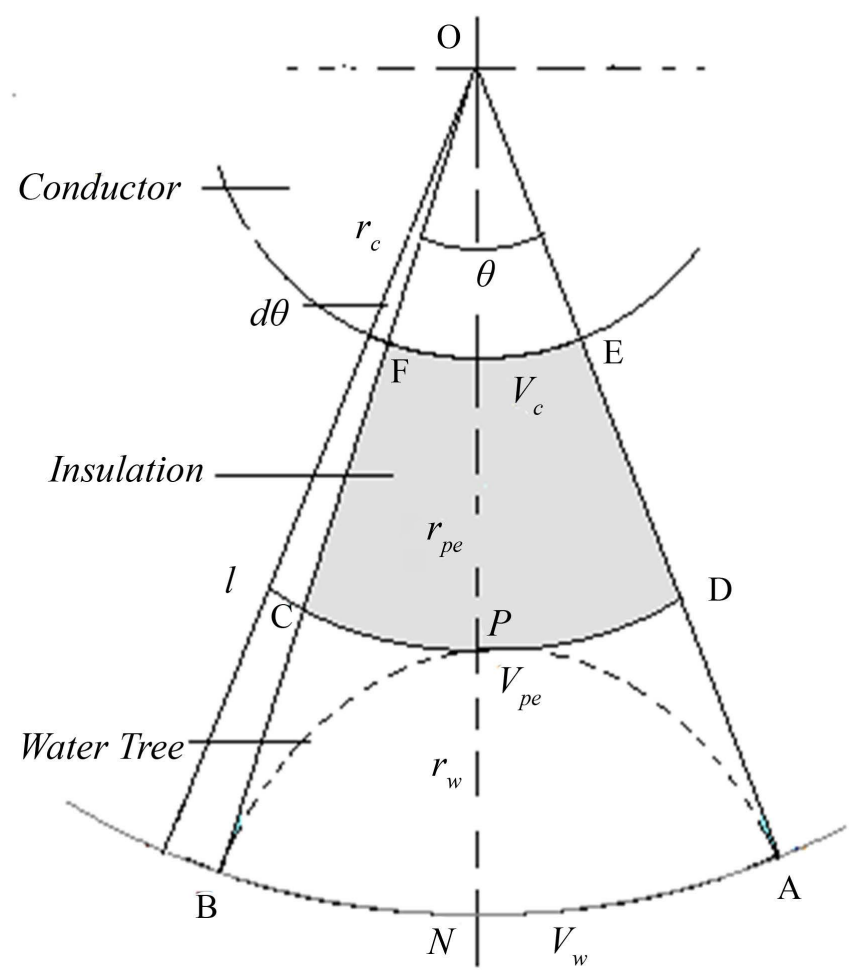

Figure 5. A Section of water tree degraded insulation.

circular cross-section of an underground cable containing a vented water tree, is presented. To simplify the computations, the water treed section is approximated to the section ABCD while the section DEFC is undegraded XLPE between the water treed section and the conductor $\mathrm{O}$. The radial distance $\overline{\mathrm{NO}}$ and $\overline{\mathrm{PO}}$ of the root and the front of the water tree from the center of the conductor is denoted by $r_{w}$ and $r_{p e}$ respectively, while the angle subtended at $\mathrm{O}$ by the water treed section is $\theta^{\circ}$. The water treed region averagely has a higher dielectric permittivity $\varepsilon_{w}$ than that of the surrounding insulation material, which has a constant dielectric permittivity $\varepsilon_{p e}$ [15]. Under the influence of a time-varying electric field, the water treed region exhibits a dynamic permittivity behavior, which is dependent on the density of the network of dendritic water inclusions in the region. This difference in permittivity between the water treed region and pure XLPE confers on each of them a unique capacitive property. Hence, the two regions may be considered as two different capacitors $C_{w}$ and $C_{p e}$ connected in series. The water tree dielectric permittivity $\varepsilon_{w}$, radial growth $l_{w}$, and the angular expansion $\theta$ all changes with time as the region grows. The changes in these three quantities with respect to time accounts for the dynamic shape change of the water tree. It is on this shape change principle that the derivation and calculation of water tree dynamic capacitance are based.

\subsection{Capacitance of Vented Water Tree}

For insulation failure studies, it is customary to model insulation degradation as some measurable quantity whose value during the degradation process, may be 
computed. Since the insulation failure process results in a progressive change in the permittivity of its material, the capacitance of a failing insulation has been used as a measurable index of the extent of the failure process. The overall capacitance of a cable during the failure process is determined by the capacitance of the water treed region [7]. This capacitance and its change with respect to time is a function of the number and advancement of water trees within the insulation system. Consequently, it's successful modeling as a function of time is a means of computing and tracking the insulation degradation process.

Regarding the geometry of Figure 5, when a water treed cable is energized, the conductor's surface, water tree/insulation interface, and water tree root assume potentials $V_{c}, V_{p e}$, and $V_{w}$, respectively. The potential difference $V_{d}$ between $V_{p e}$ and $V_{w}$ is given by:

$$
V_{d}=-\int E \mathrm{~d} r .
$$

The electric field $E$ at any point $r$ within the water treed space having a dielectric permittivity $\varepsilon_{w}$ and bounded by the potentials $V_{p e}$, and $V_{w}$ is given by:

$$
E=\frac{\lambda}{\varepsilon_{w} r \theta}
$$

where $\lambda$ is the charge per unit length of the region.

Substituting (2) into (1), and integrating with respect to $r$ in the limit $r_{w} \leq r \leq r_{p e}$, the potential difference $V_{d}$ is given by

$$
V_{d}=V_{w}-V_{p e}=-\frac{\lambda}{\varepsilon_{w} \theta} \int_{r_{p e}}^{R} \frac{1}{r} \mathrm{~d} r
$$

where $r_{w}=\overline{\mathrm{NO}}$ is the radius $R$ of the cable.

With the inception of water treeing, the point of moisture ingression into the insulation assumes the ground potential so that $V_{w} \cong 0$.

Hence,

$$
V_{d}=\frac{\lambda}{\varepsilon_{w} \theta} \log _{\mathrm{e}} \frac{R}{r_{p e}}
$$

Since $\lambda=\frac{Q}{L}(\mathrm{C} / \mathrm{m})$, considering a unit length of cable,

$$
V_{d}=\frac{Q}{\varepsilon_{w} \theta} \log _{\mathrm{e}} \frac{R}{r_{p e}}
$$

Hence, the capacitance $C_{w}$ of the water treed region is given by

$$
C_{w}=\frac{Q}{V_{d}}=\varepsilon_{w} \theta\left(\ln \frac{R}{r_{p e}}\right)^{-1} .
$$

As shown in Figure 5, $l, r_{c}, l_{w}$, and $\varepsilon_{0}$ are insulation thickness, conductor radius, water tree length, and permittivity of free space $=8.85 \times 10^{-12} \mathrm{~F} / \mathrm{m}$, respectively. Also, it may be seen that $r_{p e}=\left(R-l_{w}\right)$. Using the relative permittivity of each of the two distinct material media $\varepsilon_{r, w}$ and $\varepsilon_{r, p e}$ and noting that the parameters $l_{w}, \theta$, and $\varepsilon_{w}$ are each a function of the water treed region 
whose characteristics changes with time, the capacitance of the water-treed region may be written as

$$
C_{w}=8.85 \times 10^{-12} \varepsilon_{r, w}(t) \theta(t)\left[\log _{\mathrm{e}}\left(\frac{R}{R-l_{w}(t)}\right)\right]^{-1} .
$$

As may be observed from (6), the three components of the expression, which are all function of time, are the electrical permittivity $\varepsilon_{r, w}$, circumferential, and radial dimensions $\theta$ and $l_{w}$, respectively.

$$
C_{w}=f\left(r, \theta, \varepsilon_{w}\right)
$$

where $r=r(t), \theta=\theta(t)$ and $\varepsilon_{w}\left(l_{w}\right)$.

But, $l_{w}=l_{w}(t)$, hence,

$$
C_{w}=f\left[r(t), \theta(t), \varepsilon_{w}(t)\right]
$$

And

$$
C_{w}=C_{w}(t)
$$

we proceed to derive explicit expressions for each in the following sections.

\subsection{Water Tree Permittivity}

Figure 6 shows the simplified geometry of a vented water tree growing within a section of XLPE insulation and the variation of the permittivity with the growth. According to [7] [16], and [17], water inclusions and the interlinking channels making up the water tree are densest at the root. That density decreases towards the front of the water tree. Similarly, the relative permittivity has been found to follow the same trend. According to [16], it decreases exponentially from a value

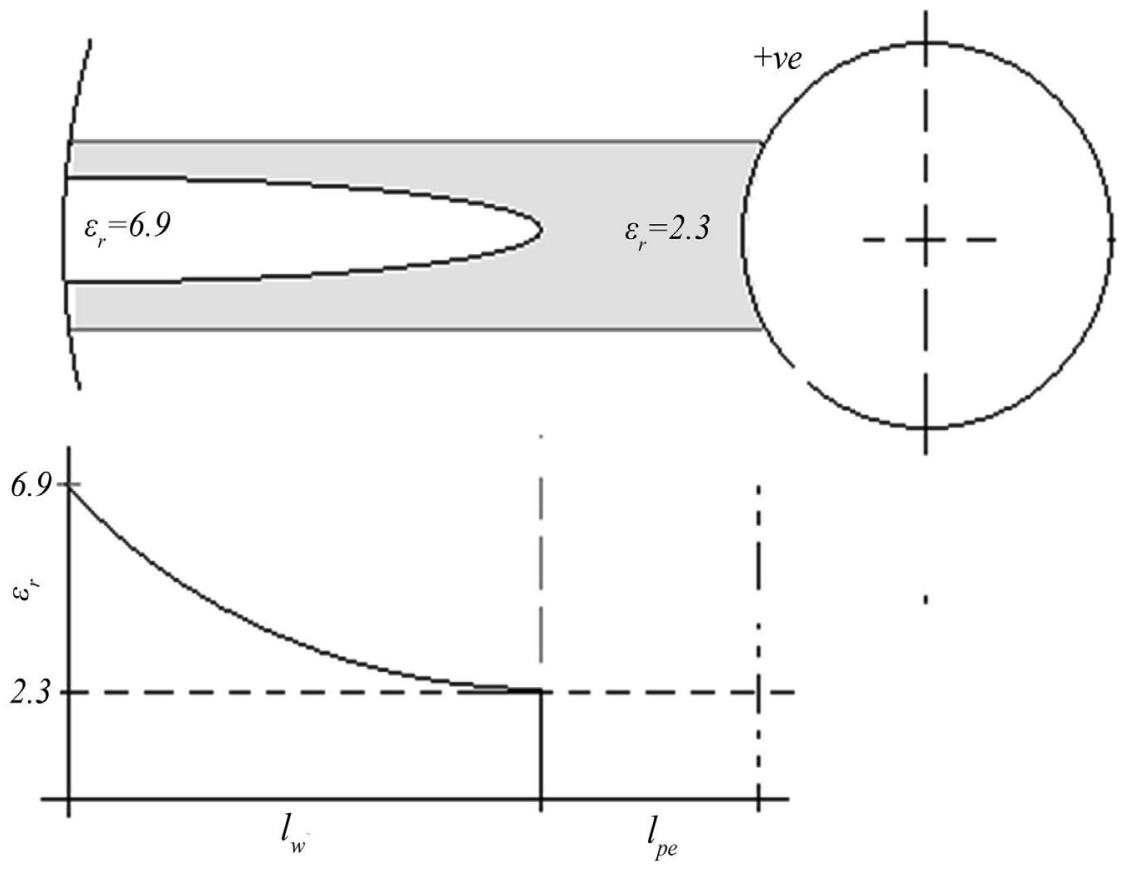

Figure 6. Water tree permittivity variation with length. 
of about 6.9 at the root to 2.3 at the front. This value has been adopted in this paper. The argument for a value of 6.9 appears to be more plausible in view of the fact that water treed insulation only contains a microscopic quantity of moisture and remains predominantly insulation.

In modeling the relationship between water tree capacitance and water tree length, [7] also used COMSOL Hyperphysics software to develop a graphical illustration that shows that water tree capacitance indeed varies with the length of water trees as a decreasing exponential function. We mathematically present this as:

$$
C_{w} \propto \frac{1}{f\left(l_{w}\right)}
$$

Let

$$
f\left(l_{w}\right)=\mathrm{e}^{k l_{w}}
$$

Then,

$$
\Rightarrow C_{w} \propto \mathrm{e}^{-k l_{w}}
$$

but $C \propto \varepsilon$, hence

$$
\varepsilon_{w} \propto \mathrm{e}^{-k l_{w}}
$$

thus, we write

$$
\varepsilon_{r, w}=A \mathrm{e}^{-k l_{w}}
$$

subject to:

$$
\varepsilon_{r w}=f\left(l_{w}\right)=\left\{\begin{array}{l}
6.9, l_{w} \rightarrow 0 \\
2.3, l_{w} \rightarrow 1.0 \text { p.u. }
\end{array}\right.
$$

where $A$ and $k$ accounts for the material constants of the insulation and $l_{w}=l_{w}(t)$.

By applying (14) to (13), we obtain $A=6.9$ and $k=1.10$. Consequently,

$$
\varepsilon_{r w}=\varepsilon_{r w}(t)=6.9 \mathrm{e}^{-1.10 l_{w}^{\prime}(t)}
$$

where $l_{w}^{\prime}$ is the normalized water tree length given by

$$
l_{w}^{\prime}(t)=\frac{l_{w}(t)}{l} .
$$

\subsection{Water Tree Radial Growth}

As earlier proposed, a vented water tree is approximately parabolic. The general expression for such a parabola takes the form

$$
y=a x^{2} \pm c .
$$

The constants $a$ and $c$ controls the width along the $x$-axis and depth along the $y$-axis of the parabola, respectively. Applying this fact to water tree growth, it implies that a controls the expansion of the root of the water tree while $c$ controls its radial growth. Since each of these growths takes place with respect to time, (17) may be recast as 


$$
y=f(x, t)=a(t) x^{2}+c(t) .
$$

Based on the description and images of real-time vented water tree growth seen under the microscope and described by [14] and [18], radial growth was found to be faster than the angular expansion. Guided by this description, we approximated functions of best fit for the two coefficients as:

$$
a(t)=\mathrm{e}^{-0.125 t}
$$

and

$$
c(t)=\left(R-0.000002 \mathrm{e}^{0.4 t}\right),
$$

where $R$ is the radius of the circle described by the cable's circular cross-section. Hence, (18) modifies to the general form

$$
f(x, t)=\mathrm{e}^{-0.125 t} x^{2}+\left(R-0.000002 \mathrm{e}^{0.4 t}\right) .
$$

Equation (21) is the vented water tree shape-changing equation describing water tree growth with time. Using (21), water tree length at a given time may be computed from

$$
l_{w}(t)=R-f(0, t)=R-c(t) .
$$

\subsection{Water Tree Circumferential Growth}

Figure 7 shows a vented water tree growing from the insulation/screen interface towards the conductor. Both are situated in the $x-y$ cartesian plane with the origin at the center of the conductor $\mathrm{O}$. The geometry shows the root of the water tree intersecting the circular outline of the cable at $A\left(x_{1}, y_{1}\right)$, and $B\left(x_{2}, y_{2}\right)$ respectively. To compute $\theta(t)$, which represents the circumferential growth of the water tree's root, the circle $y^{2}=R^{2}-x^{2}$ made by the cable's cross-section is equated to (18), which describes the water tree at any given time. The intersection points $\left(x_{1}, y_{1}\right)$ and $\left(x_{2}, y_{2}\right)$ may be determined from

$$
f(x, t)=a(t) x^{2}+c(t)=\sqrt{R^{2}-x^{2}} .
$$

We obtain solutions $x_{1}$ and $x_{2}$ to (23) as expressed in (24) where $x_{1}$ is positive, and $x_{2}$ is negative.

$$
x=\sqrt{\frac{-[2 a(t) c(t)+1] \pm \sqrt{\left.\{[2 a(t) c(t)+1]\}^{2}-4(a(t))^{2}[c(t))^{2}-R^{2}\right]}}{2(a(t))^{2}}}
$$

Considering only $x_{1}$, then $y_{1}$ of the intersection, $\left(x_{1}, y_{1}\right)$ can be obtained from:

$$
y_{1}=f\left(x_{1}, t\right)=a(t) x_{1}^{2}+c(t)
$$

Finally, from the geometry of Figure 7, $\theta(t)$ is obtained from

$$
\theta(t)=2\left[\frac{\pi}{2}-\arctan \left(\frac{y_{1}}{x_{1}}\right)\right]
$$




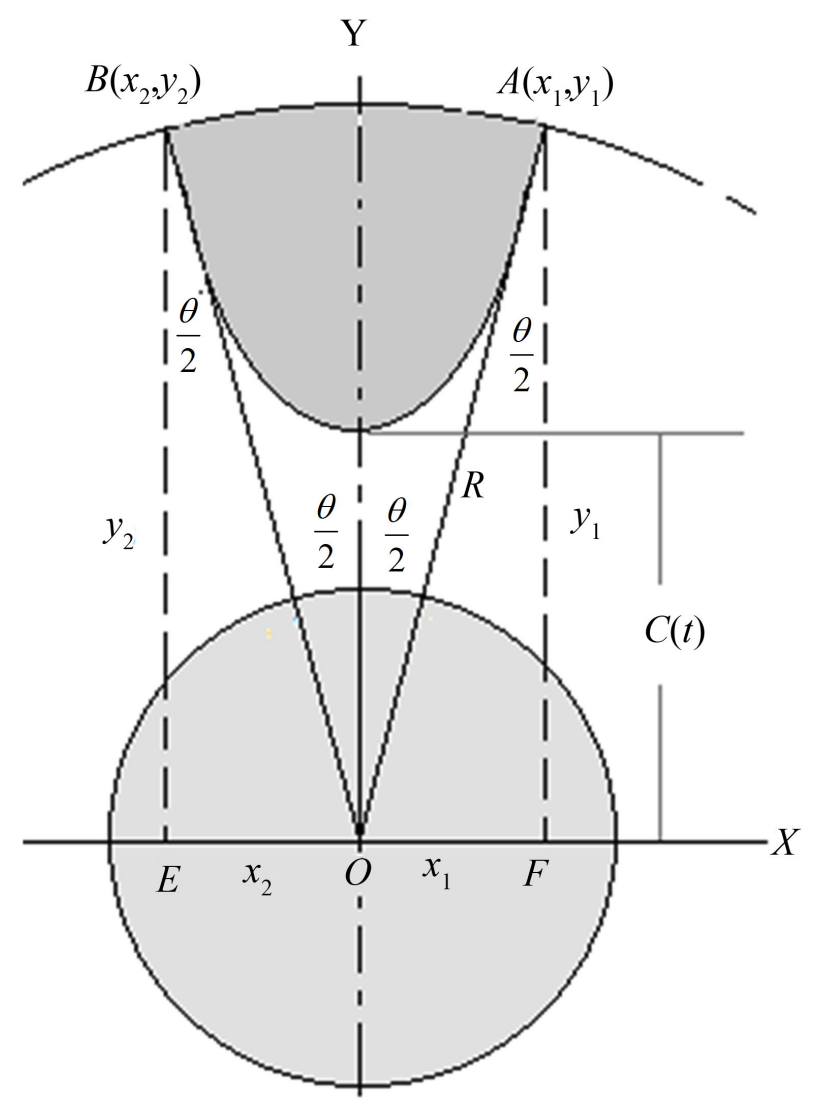

Figure 7. A part of the cross-section of cable with a single water tree.

Similarly, the arc length at the outer sheath of the water tree region at the time is obtained as $2 R \theta(t)$, and that at the front of the water tree region as $2 c(t) \theta(t)$.

\section{Result and Discussion}

\subsection{Computation of Water Tree Capacitance}

The capacitance of the water tree at any given time $t_{k}$ during its growth may now be computed by first obtaining the values of $\varepsilon_{r, w}(t), l_{w}(t)$ and $\theta(t)$, from (15), (22) and (26) at time $t_{k}$. Substituting the values obtained into (6), the capacitance of the water tree at any given time $t_{k}$ is obtained. Computing these values in time steps $t_{0}, t_{1}, t_{2}, \cdots, t_{n}$, a set of values of the capacitance of the water tree was obtained. Using the MS Excel chart wizard, a plot of capacitance against normalized water tree length $l_{w}^{\prime}(t)$ and degradation time $T_{\text {deg }}$, in years were effected. Both are shown in Figure 8 and Figure 9, respectively, from which it may be observed that water tree capacitance decreases exponentially with its growth and time.

\subsection{Estimation of Insulation End of Life}

We applied the parameters of a $70 \mathrm{~mm}^{2}, 12.7 / 22 \mathrm{kV}$, single-core, copper, XLPE underground cable having a conductor radius of $4.95 \mathrm{~mm}$, and insulation thickness $5.50 \mathrm{~mm}$ to (20). It was revealed that at $t=19.8$ years, the water tree 


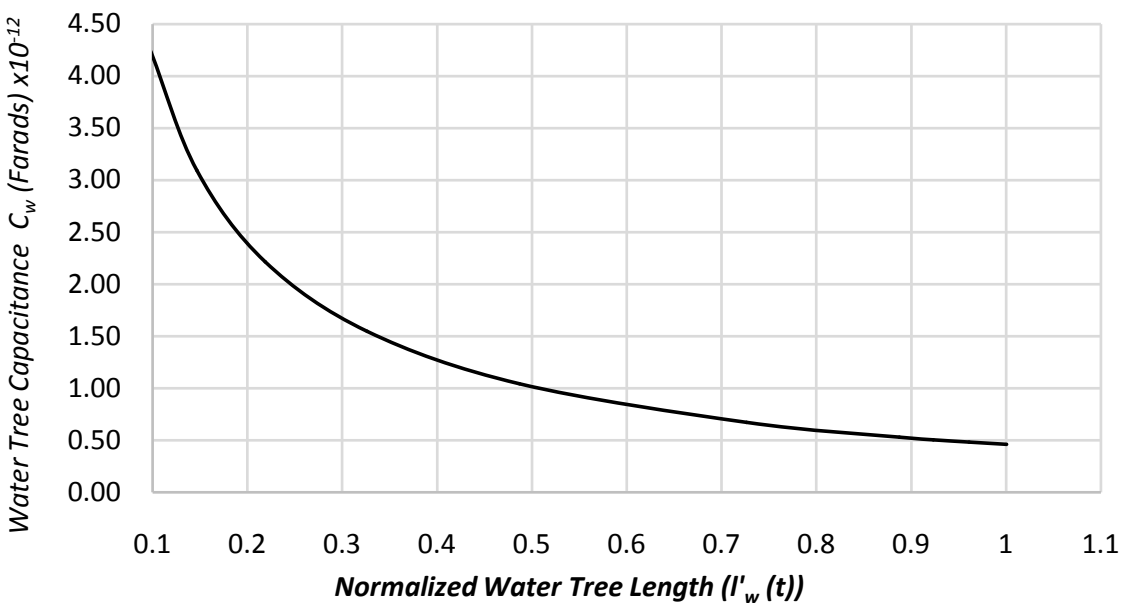

Figure 8. The plot of capacitance against water tree length.

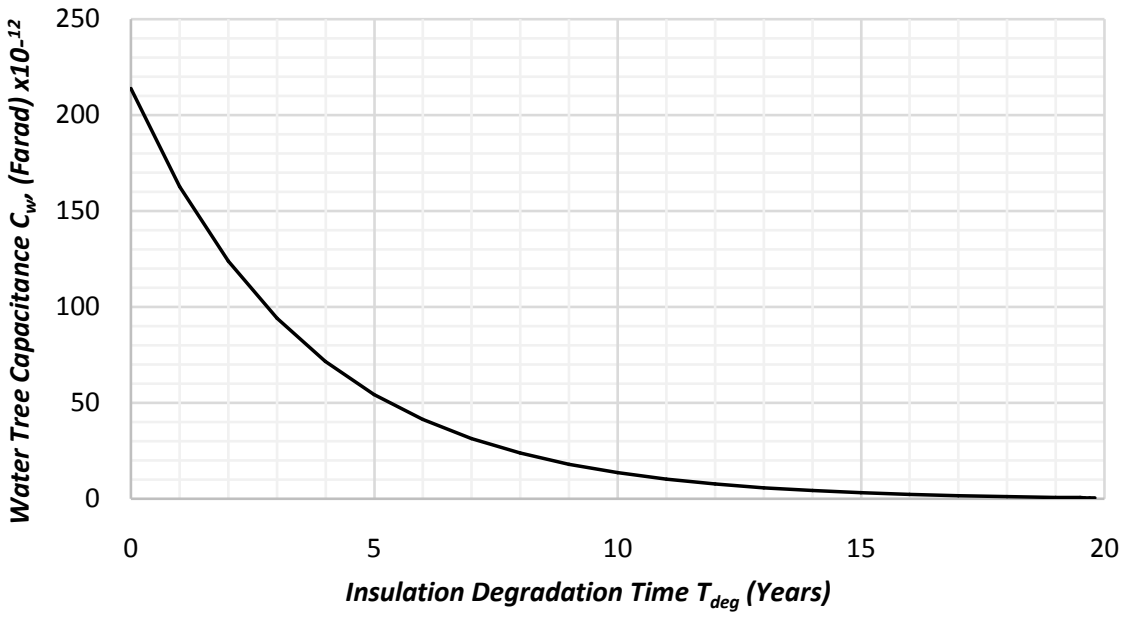

Figure 9. The plot of capacitance against degradation time.

breaches the insulation entirely and reaches the conductor (with its length the same as the insulation thickness), which is the condition for insulation breakdown. Disregarding the stochasticity that is peculiar to the water treeing problem, our shape-changing equation was able to predict an inception-insulation breakdown time, which falls within the range reported in the literature by [19].

A further performance test of the dynamic models was done by comparing it graphically with two other models (Chen's and Stucki's) [7] [20], that were found in the literature. Figure 10 illustrates this.

While Chen's model was built analytically on the properties of XLPE cables just like our dynamic model (DM), Stucki's model was developed from measurements of water tree capacitance and its length. It was carried out on the field aged samples of Polyethylene (PE) insulation from a cable retired from service. Our model follows the same trend as Chen's even though there is a difference of an order of magnitude between them. This may be attributed to the fact that the authors used a relative permittivity of 88 for the computation of water tree capacitance, while a value of 6.9 was used in this paper for reasons earlier stated. 


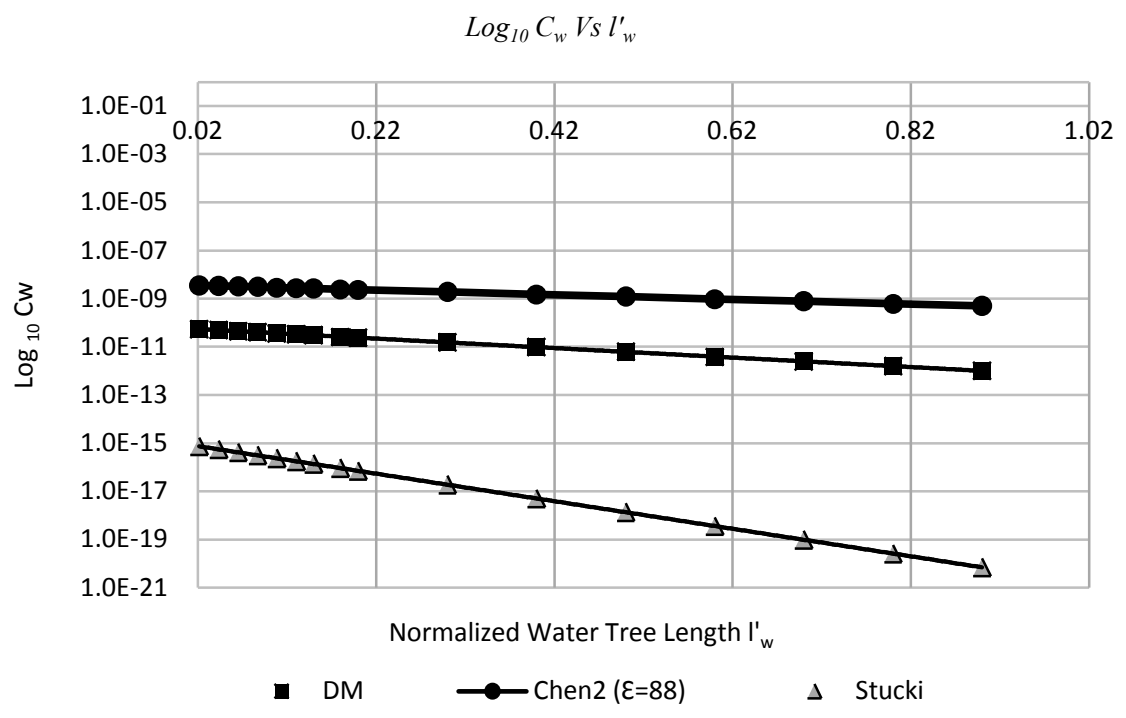

Figure 10. Model comparison for validation.

Apart from this difference, we can say that there is a significant correlation between the two models. However, our model is uncorrelated with Stucki's. This may be because PE is known to be prone to abrasion and is less stable in the presence of chemical agents than XLPE. This fact may affect water treeing dynamics in the material and the value of the measured capacitances. However, the operating environment of the cable before its retirement from service, the circumstances of its retirement, and other factors related to its years of service is unknown. Hence, no firm conclusion can be drawn to justify its behavior when compared with our dynamic model and Chen's model.

\section{Conclusion}

This paper has presented a detailed methodology for developing a dynamic growth model of water tree for insulation degradation tracking and breakdown anticipation. The model formulates a water tree shaping function of time, which led to two time-varying predictive variables, namely, water tree length and water tree capacitance. A significant strength of the model is in the computation of a cable's insulation end of life. In the future, the randomness in the growth and shape of water trees may be factored into its modeling and considered as an area of further studies to improve it. The development of this model is a precursor to additional studies and further modeling activities that are expected to result in the development and testing of methods and systems for anticipation and detection of self-clearing fault conditions in underground cable systems. This condition, which usually precedes final insulation failure is highly evasive. Identifying it and tracking its onset is useful in preventing unannounced underground feeder outages that usually arise from insulation's final failure.

\section{Conflicts of Interest}

The authors declare no conflicts of interest regarding the publication of this paper. 


\section{References}

[1] Thue, W. (2005) Basic Dielectric Theory of Cables. In: Electrical Power Cable Engineering, Marcel Dekker Inc., New York, 11-19.

[2] Sletbak, J. (1979) A Theory of Water Tree Initiation and Growth. IEEE Transactions on Power Apparatus and Systems, PAS-98, 1358-1365.

https://doi.org/10.1109/TPAS.1979.319337

[3] Steennis, E. (1989) A Thesis on Water Treeing: The Behaviour of Water Trees in Extruded Cable Insulation. Eindhoven.

[4] Radu, I., Acedo, M., Filipini, J.C., Notingher, P. and Frutos, F. (2006) The Effect of Water Treeing on the Electric Field Distribution of XLPE Consequences for the Dielectric Strength. IEEE Transactions on Dielectrics and Electrical Insulation, 7, 860-868. https://doi.org/10.1109/94.892001

[5] Toyoda, T., Mukai, S., Ohki, Y., Li, Y. and Maeno, T. (2001) Estimation of Conductivity and Permittivity of Water Trees in PE from Space Charge Distribution Measurements. IEEE Transactions on Dielectrics and Electrical Insulation, 8, 111-116. https://doi.org/10.1109/94.910433

[6] Burkes, K., Makram, E. and Hadidi, R. (2014) Modeling the Effect of Water Trees Inside Tape Shield and Concentric Neutral Cables. Proceedings of the 2014 COMSOL Conference, Boston, MA.

[7] Chen, Q., Burkes, K., Makram, E., Hadidi, R. and Xu, X. (2014) Capacitance of Water Tree Modeling in Underground Cables. Journal of Power and Energy Engineering, 2, 9-18. https://doi.org/10.4236/jpee.2014.211002

[8] Alijagic-Jonuz, B., Morshuis, P.H.F., Van Breen, H.J. and Smith, J.J. (2001) Detection of Water Trees in Medium Voltage Cables by Recovery Voltage Measurement without Reference Measurements. Proceedings of the 20001 IEEE 7 th International Conference on Solid Dielectrics, Eindhoven, 25-29 June 2001, 504-507.

[9] Burkes, K.W. and Makram, E.B. (2015) Water Tree Detection in Underground Cables Using Time Domain Reflectometry. IEEE Power and Energy Technology Systems Journal, 2, 53-62. https://doi.org/10.1109/JPETS.2015.2420791

[10] Chen, Q. and Xu, X. (2016) Early Warning of Water Tree Presence in Long Distance Underground Cable through Extrapolation-Comparison Method. 2016 IEEE/PES Transmission and Distribution Conference and Exposition, Dallas, TX, 3-5 May 2016, 1-5. https://doi.org/10.1109/TDC.2016.7519937

[11] Hvidsten, S., IIdstad, E. and Faremo, H. (1998) Mechanisms Causing Non-linear Dielectric Response of Water Treed XLPE Cables. Proceedings of the 1998 IEEE 6 th International Conference on Conduction and Breakdown in Solid Dielectrics, Vasteras, Sweden, 22-25 June 1998, 73-78.

[12] Burkes, K.W. (2014) Water Tree Analysis and On-Line Detection, Algorithm Using Time Domain Reflectometry.

[13] Dubickas, V. (2006) On-line Time Domain Reflectometry Diagnostics of Medium Voltage XLPE Power Cables. Licentiate Thesis, Royal Institute of Technology, Stockholm, Sweden.

[14] Alexeff, T., Blalock, V., Pace, M.O. and Williams, B.E. (1993) Observation of Water-Tree Growth in Polyethylene in Real-Time. IEEE Electrical Insulation Magazine, 9, 14-16. https://doi.org/10.1109/57.234674

[15] Nakamura, S., Ozaki, T. and Ito, N. (2002) Change of Dielectric Property with Water-Treed Region. IEEE Transactions on Dielectrics and Electrical Insulation, 9, 329-334. https://doi.org/10.1109/TDEI.2002.1007694 
[16] Acedo, M., Frutos, F., Torre, M. and Filippini, J.C. (1995) The Cylindrical Capacitive Model for Water Treeing Degradation in Extruded HV Cables. Proceedings of IEEE 5 th International Conference on Conduction and Breakdown in Solid Dielectrics, Leicester, England, 10-13 July 1995, 661-665.

[17] Notingher, P.V., Radu, I. and Filippini, J.C. (1995) Electric Field Calculations in Polymers in the Presence of Water Trees. Proceedings of IEEE 5 th International Conference on Conduction and Breakdown in Solid Dielectrics, Leicester, 10-13 July $1995,666-670$.

[18] Karhan, M., Yılmaz, A.E. and Uğur, M. (2017) Investigation of the Effect of Solution Conductivity on the Growth Rate and Shape of Water Trees Observed in Distribution Cables. Istanbul University Journal of Electrical and Electronics Engineering, 17, 3445-3451.

[19] Sutton, S. (2011) A Life Cycle Analysis Study of Competing MV Cable Materials. 21 st International Conference on Electricity Distribution, Frankfurt.

[20] Stucki, F. and Schonenberger, A. (1992) Dielectric Properties of Single Water Trees. Proceedings of the 4th International Conference on Conduction and Breakdown in Solid Dielectrics, Sestri Levante, 22-25 June 1992, 373-377. 